\title{
Analyzing the Impact of different Order Policies on the Supply Chain Performance
}

\author{
Volker Stich, Daniel Pause, Matthias Blum \\ Institute for Industrial Management (FIR), Aachen, Germany \\ \{daniel.pause\} @fir.rwth-aachen. de
}

\begin{abstract}
Influenced by the high dynamic of the markets and the steadily increasing demand for short delivery times the importance of supply chain optimization is growing. In particular, the order process plays a central role in achieving short delivery times and constantly needs to evaluate the trade-off between high inventory and the risk of stock-outs. However, analyzing different order strategies and the influence of various production parameters is difficult to achieve in industrial practice. Therefore, simulations of supply chains are used in order to improve processes in the whole value chain. The objective of this research is to evaluate two different order strategies $(\mathrm{t}, \mathrm{q}, \mathrm{t}, \mathrm{S})$ in a four-stage supply chain. In order to measure the performance of the supply chain the quantity of the backlog will be considered. A Design of Experiments approach is supposed to enhance the significance of the simulation results.
\end{abstract}

Keywords: Order $\bullet$ Supply Chain $\bullet$ System Dynamics $\bullet$ Inventory Management - Design of Experiments

\section{Introduction}

Today, manufacturing companies are confronted with the influences of a dynamic environment and the continuously increasing planning complexity [1]. Reduced time to markets, rising product diversity as well as complex multi-tier and world-spanning supply chains are faced with growing inter-connectivity of production machinery, enterprise resource planning systems and manufacturing execution systems. Due to globalization, the number of market participants rises resulting in a growing competition amongst the individual companies [2].

In order to remain profitable as a business, the industrial enterprises in high-wage countries must identify cost carrier of the production process in order to reduce unnecessary costs. This is why companies focus on the production steps with a high share of added value and reduce the depth of production [3]. A strong trend towards reduced inventory is sensed so that components are delivered "just-in-time" (JIT) for the production. Accordingly, the process of ordering must be designed in a way which ensures a smooth production. As part of inter-company value chains the individual view of ordering is not adequate anymore. Rather, the analysis and optimization of the whole supply chain continues to gain importance [4].

Considering these problems, companies lack on an efficient design of their order processes. In order to create a better understanding of complex interdependencies in the supply chain a simulation model of a four-stage supply chain was designed (sub-supplier, supplier, manufacturer and customer).

In this research $\mathrm{t}, \mathrm{q}$ and $\mathrm{t}, \mathrm{S}$ order policies are going to be implemented in a supply chain model. In order to further investigate the interactions of the parameters in the supply chain, a Design of Experiments approach was used. Hereby, the interactions of the parameters are investigated and principles how to design an efficient supply chain 
are derived. The emphasis is put on the interplant relation instead of the internal production itself.

The remainder of this paper is organized as follows: First, we give a short introduction about the today`s challenges for manufacturing companies and further discuss related work in Section 2. Next, we introduce the methodology of System Dynamics in Section 3. Section 4 focuses on the description of the simulation model and in section 5 we present the results of predefined simulation scenarios. Finally, we conclude in Section 6 and highlight future work.

\section{State of the Art}

Due to the close link between ordering, inventory management and production a separate analysis of these sections is not sufficient. Thus, the emphasis is put on the optimization of all companies involved in the value-added process (supply chain). To investigate the cooperation and acting of a supply chain various research approaches already exist. In the following, these approaches are outlined.

Moizer et al. (2014) examine the advantages of a close cooperation between the manufacturer and its suppliers of a retail supply chain and the influence of efficiency and performance. A simulation was used based on a trial group consisting of 12 retailers in the US. It was shown that collaboration can cut costs, risks and inventory for both the retailer and their suppliers [5].

Langroodi and Amiri (2016) investigate the choice of the most appropriate region for order placements in a five stage multi-product supply chain, consisting of a customer, an incorporate retailer, manufacturer, material distributor and supplier, in four different regions using a System Dynamics model. A scenario analysis with varying costs and demands was conducted. The model aims to minimize the costs of orders between two stages consisting of transport, price for the product and order placement and thus choose the best supplier [6].

Hishamuddin et al. (2015) analyze disruptions of supply and transportation on the system's total recovery costs and other performance measures in a three stage supply chain with multiple suppliers. Thus, different scenarios of disruptions were established to evaluate system costs and stock-outs. It was shown that transportation disruptions have more damaging effects than supply disruptions due to the higher lost sales quantity. In addition, disruptions in the earlier stages have a higher negative impact to the supply chain compared to later disruptions [7].

Li et al. (2016) examine the dynamic risks effects in a chemical supply chain transportation system. Therefore, a System Dynamics model was built and risk scenarios were established regarding the probability and consequence severity in order to compare order fulfillment rate, transportation and inventory level to measure the performance. The major sources of risks transpired among other as breakdown in core operations, inappropriate choice of service provider and lack of inventory management. The researchers used only a questionnaire as the input for various risk scenarios, which could be a source of bias. Thus, it would be necessary to use a more extensive data source [8].

This paper continues a previous research which focused on the simulation of $s, q$ and $\mathrm{s}, \mathrm{S}$ order policies. The previous paper was called "A simulation based approach to investigate the procurement process and its effect on the performance of supply chains" [9]. Combining the model components and results of both papers, further research will focus on analyzing and comparing all four order policies as a whole. 


\section{Methodology}

System Dynamics is a computer-aided approach for modeling, simulating, analyzing and designing dynamic and complex issues in socio-economic systems. Initially called Industrial Dynamics [10] the field developed from the work of Jay W. Forrester at the Massachusetts Institute of Technology.

Simulation models based on System Dynamics contain four different types of elements [11]:

1. Levels represent state variables of the system

2. Flow variables symbolize temporal change of the state variables

3. Auxiliary variables are used for decision rules describing casual relations

4. Constants are parameters to be set for the simulation

Supply chains mainly consist of inventory (information or material) as time based variables and flows as activities (transport of material and information). Decisions steer running activities and thus the state of the system [12]. A superior aspect to other simulation models is the possibility of feedback loops within the model. Thus, it is suitable for analyzing complex problems [13]. A common way to analyze a system's behavior using System Dynamics is a scenario analysis. This was done by using the tool Vensim.

\section{Description of the Simulation Model}

\subsection{Model Structure}

The model consists of a sub supplier, a supplier, a manufacturer and a customer (Figure 1). Between the respective supply chain partners a material flow and an information flow is taking place. The sub supplier serves as an infinite source of order items and the customer is able to create different demand situations. The supplier and the manufacturer are modelled according to a simplified business structure, which is described in the following paragraph.

The business structure of both the supplier and the manufacturer are composed of an arrival warehouse for incoming goods, a quality check (QC) for the incoming goods, a production and a shipping warehouse from which the products are delivered to the customer.

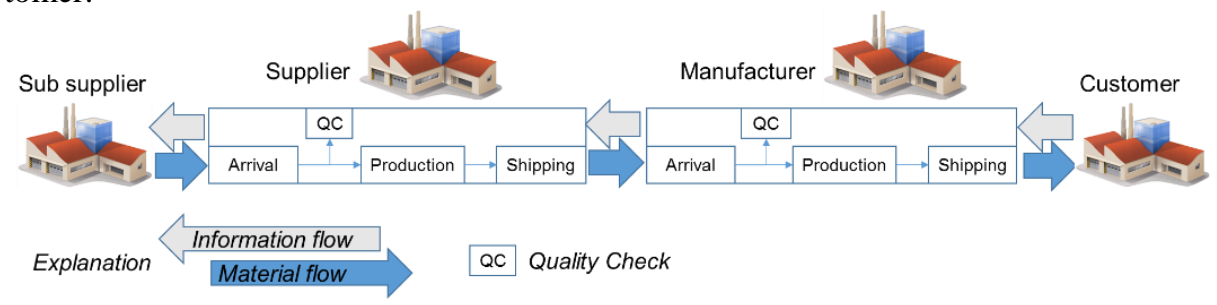

Fig. 1. Model structure

The parameters contained in the model are shown in Table 1. Conducting a scenario analysis maximum stock level, periodic time, fixed order quantity and production rate were defined for both the supplier and the manufacturer. 
Table 1. Parameters in the simulation model for the supplier and the manufacturer

\begin{tabular}{lll}
\hline Code & Declaration & Setting Range \\
\hline HB & Maximum stock level Supplier & $500-2000$ pieces \\
\hline HB 0 & Maximum stock level Manufacturer & $500-2000$ pieces \\
\hline L & Periodic time Supplier & $2-14$ days \\
\hline L0 & Periodic time Manufacturer & $2-14$ days \\
\hline Q & Fixed order quantity Supplier & $200-1000$ pieces \\
\hline Q0 & Fixed order quantity Manufacturer & $200-1000$ pieces \\
\hline PLL & Production Rate Supplier & $500-10.000$ pieces/day \\
\hline PL H & Production Rate Manufacturer & $500-10.000$ pieces/day \\
\hline
\end{tabular}

The customer demand is induced by an Excel based data generator. Thus, based on several parameters different demand situations can be applied to the simulation model. An expected demand and a standard variation need to be specified prior to the simulation as well as the initial situation with regard to a so-called trend, season or a constant demand.

\subsection{Order Process}

In the beginning of the simulation a certain stock is available in the shipping warehouse from which the demand is satisfied. According to a constant time interval a new order is placed at the supplier. The order quantity varies depending on the order policy investigated. This paper puts emphasis on frequent order points ( $\mathrm{t}, \mathrm{S}$ and $\mathrm{t}, \mathrm{q}$ order policy), because order policies using a variable order point has already been investigated in a previous research paper at APMS 2016. Order policies with frequent order points can have two different modes for determine the order quantity. When using a t,S strategy the order quantity varies due to the stock replenishment up to a maximum stock level. Whereas in the case of a t,q strategy a fix quantity is ordered every time regardless of the maximum stock level [14].

\section{$5 \quad$ Results of the Simulation}

Two different order policies with frequent order points ( $\mathrm{t}, \mathrm{s}$ and $\mathrm{t}, \mathrm{q})$ has been analyzed based on different scenarios of demand situations (seasonal, trend and stationary). The results were compared by evaluating the quantity of the backlog. However, the results of the backlog did not differentiate much in the scenarios of a seasonal, trend and stationary demand pattern. This is why the results presented in this chapter will only be based on seasonal demand pattern.

Figure 2 illustrates the backlog of manufacturer and supplier for t,S and t,q order strategy based on a seasonal demand pattern. From the figure, it can be inferred that for the considered parameters, when both manufacturer and supplier implement t,q strategy, backlog of manufacture is high (around 21000 pieces) and backlog of supplier is relatively low (around 2000 pieces) at 440th day. Likewise when both implement t,S strategy backlog of supplier is high (around 7000 pieces) and that of manufacturer is relatively low around 15000 pieces at 440th day. 

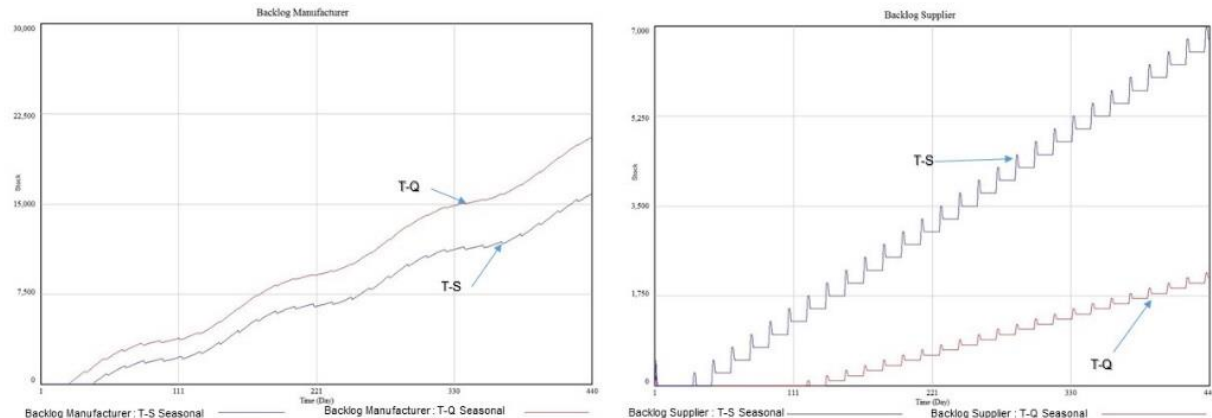

Parameters : Maximum stock level $(S)=500$ Pcs, $\quad$ Fixed order quantity $(Q)=250$ pcS,

Periodic time $(T)=14$ days

Fig. 2. Results of the Scenario analysis based on seasonal customer demand structure

Further, it can be observed from the graph of backlog manufacturer that the nature of graph is influenced by the customer demand, which is seasonal in this case. Hence a wavy graph is obtained for both t,S and t,q strategy. The backlog difference between the $t, q$ and $t, S$ along the time increases, hence a gap between both graph increases with time, and it is maximum at $440^{\text {th }}$ day. The manufacturer backlog is relatively low with $\mathrm{t}, \mathrm{S}$ strategy as the manufacturer tend to order after every time interval " $\mathrm{t}$ " till he reaches his maximum stock ' $S$ ', which would lead to more ordered parts at his end to serve the customer demand. In contrary the manufacturer backlog is high with t,q strategy as he would order only fixed order quantity ' $q$ ' after every time interval ' $t$ ' which would put manufacturer in high backlog.

Whereas in the case of supplier backlog, it can be noted that there is an initial backlog as early as day 1 for t,S strategy and then in the course of time it is zero for some time. Then the backlog is observed as the day progresses. It can be seen that, there is a sudden increase and drop of backlog, which is a result of the supplier being able to deliver the order in time for a short duration and then he will be in backlog after some time. This process repeats periodically as seen in figure 2 . The same process repeats for $t, q$ strategy, too, but the difference is that the backlog is zero for more than 100 days and then the backlog increases in the course of time with abrupt increase and decrease in between.

Based on the simulation results a Design of Experiments analysis was conducted to visualize and identify the factors that influence the backlog of delivered parts most. The main effects charts in Figure 3 illustrate the examined factors (also see Table 1) and indicates if it has a positive or negative impact on the backlog when changing from a predefined minimum to a maximum value.

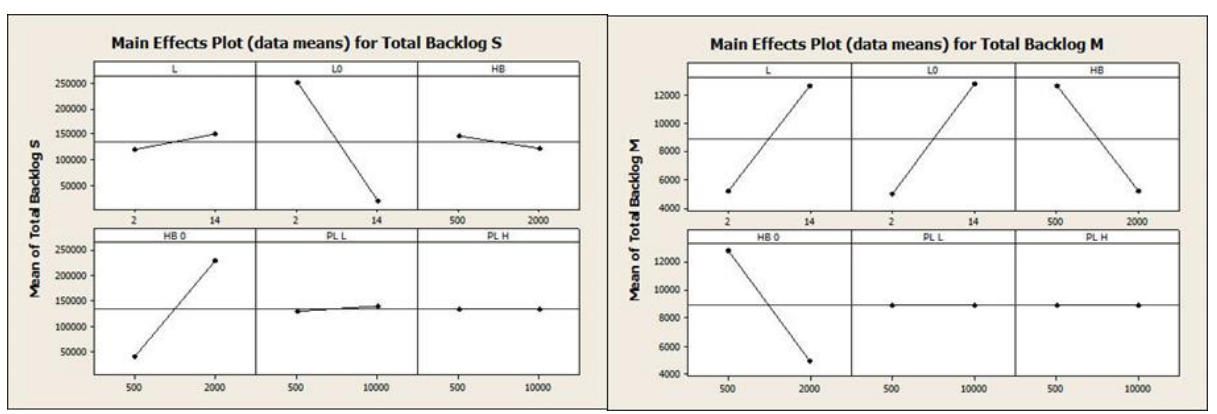

Fig. 3. Main effects chart for t,S order strategy with seasonal demand 
A horizontal line in Figure 3 implies that there is no effect on the backlog, the steeper the line the greater the influence on the backlog. Hence, there would be almost no effect of production rate of supplier (PL L) and manufacturer (PL H) on supplier and manufacture backlog. It is also observed that the greatest influence on the backlog of the manufacturer and supplier are the periodic time (L, L0) and the maximum stock level (HB, HB 0).

An interaction plot shows the interdependencies between factors when changing specific factor settings. Because an interaction can magnify or diminish main effects, evaluating interactions is extremely important.

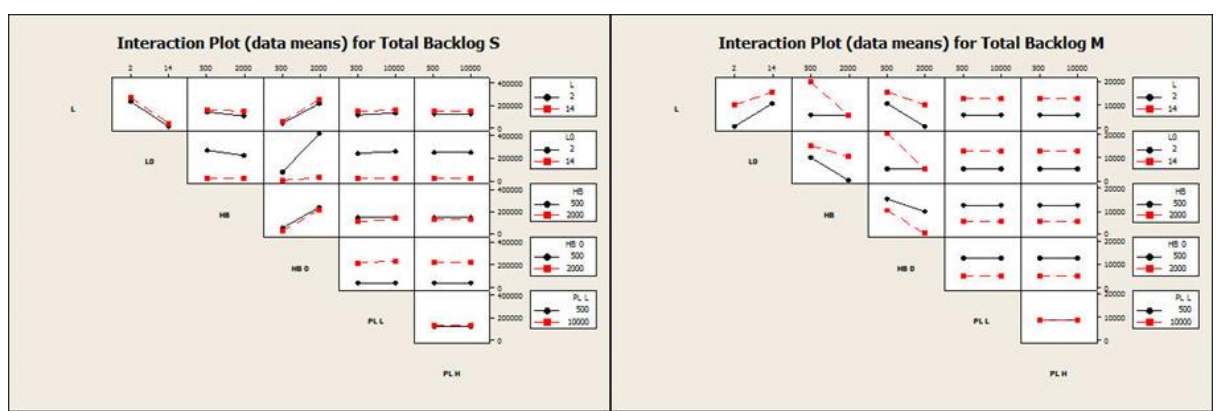

Fig. 4. Interaction plot for $\mathrm{t}, \mathrm{S}$ order strategy with seasonal demand

The lines in Figure 4 are indicating the strength of the interaction between the parameters. If the lines are parallel to each other, no interaction occurs. The more nonparallel the lines are, the greater the strength of interaction is.

Evaluating the Supplier's backlog, almost no interaction between the maximum stock of the manufacturer (HB 0) and the supplier (HB) can be detected. But it can be seen that there is an interaction between manufacturer's periodic time (L0) and maximum stock level of manufacturer (HB 0). Other parameters like production rate of supplier (PL L) and production rate of manufacturer (PL H) do not have much impact on backlog of supplier, as from figure it can be seen that, those parameters are plotted as parallel lines.

Evaluating the manufacturer's backlog, it stands out that there is a great influence between the maximum stock of the manufacturer (HB 0 ) and the periodic time manufacturer (L0). Other parameters like production rate of supplier (PL L) and production rate of manufacturer (PL H) do not have much impact on the backlog of the supplier.

Due to this fact, it would be advisable that the supplier and the manufacturer plan on their maximum stock for a decreasing backlog.

The main effects charts for t,q order strategy with seasonal customer demand are illustrated in Figure 5.

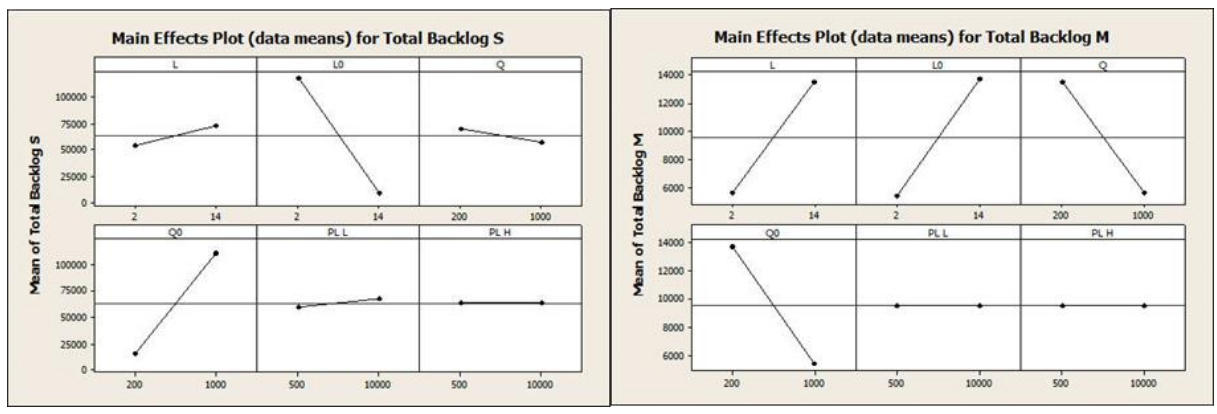

Fig. 5. Main effects chart for t,q order strategy with seasonal demand 
Similar to Figure 3 there is almost no effect of production rate of supplier (PL L) and manufacturer (PL H) on supplier and manufacture backlog. It is also observed that the greatest influence on the backlog of the manufacturer and supplier are the periodic time $(\mathrm{L}, \mathrm{L} 0)$ and the fixed order quantity $(\mathrm{Q}, \mathrm{Q} 0)$.

In the below Figure 6 an interaction plot for t,q order strategy is illustrated.

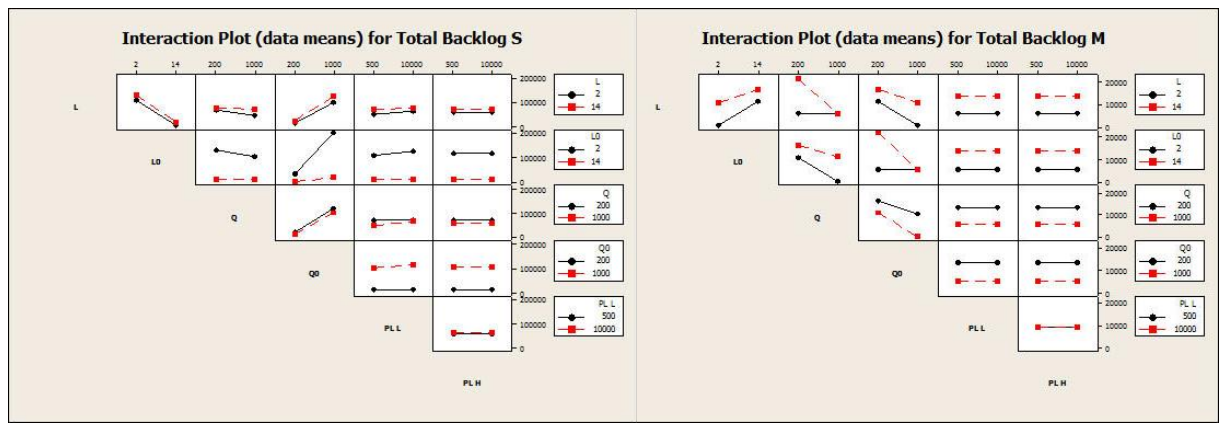

Fig. 6. Interaction plot for t,q order strategy with seasonal demand

Similar to Figure 4 the lines in Figure 6 are indicating the strength of the interaction between the parameters. Evaluating the supplier's backlog, no interaction between the fixed order quantity supplier (Q) and manufacturer (Q0) can be detected. But it can be seen that there is an interaction between manufacturer periodic time (L0) and the fixed order quantity manufacturer (Q0). Other parameters like production rate of supplier (PL $\mathrm{L}$ ) and production rate of manufacturer $(\mathrm{PL} \mathrm{H})$ do not have much impact on backlog of supplier, as those parameters are plotted as parallel lines. Evaluating the manufacturer's backlog, it stands out that there is a great influence between fixed order quantity manufacturer (Q0) and the periodic time manufacturer (L0). Other parameters like production rate of supplier (PL L) and production rate of manufacturer (PL H) do not have much impact on backlog of supplier, as those parameters are plotted as parallel lines.

\section{Outlook and further Research}

In this paper, a simulation of a four-stage supply chain was presented and two order policies were compared. After introducing the basics of ordering and inventory as well as System Dynamics, the model structure was explained and t,S and t,q order policies were chosen for a comparison.

It was shown that the periodic time and maximum stock level are main causes for the supply chain's performance. Due to the dependency of the backlog of the supplier by actions of the manufacturer, a close cooperation between all companies involved is advisable. The vendor managed inventory where the supplier manages the inventory and orders of the manufacturer is a method trying to decrease the backlog. In further investigations this method could be considered and implemented in the simulation model. Additionally, other parameter could be added to the model, which might influence the supply chain's performance e.g. costs for inventory and ordering or late delivery charges (liquidation damage) in order to further specify decision rules. Moreover, instead of using the backlog as a main measuring unit for the supply chain performance further objectives such as costs or average inventory level could be considered. 
Acknowledgements. The presented research is a result of the Cluster of Excellence (CoE) on "Integrative Production Technology for High-Wage Countries" funded by Deutsche Forschungsgemeinschaft (DFG). Within the CoE "Integrative Production Technology for High-Wage Countries" several institutes at RWTH Aachen University are conducting research on fundamentals of a sustainable production strategy. The authors would like to thank the German Research Foundation DFG for the kind support within the Cluster of Excellence „Integrative Production Technology for High-Wage Countries.

\section{References}

1. BRECHER, C, Ed., Integrative Production Technology for High-Wage Countries. Springer Heidelberg Dorbrecht London New York, 2012.

2. RUSHTON, A.; CROUCHER, P.; BAKER P.: The Handbook of Logistics and Distribution Management: Understanding the Supply Chain. 5. Auflage Kogan Page 2014.

3. WANNENWETSCH, H.: Integrierte Materialwirtschaft, Logistik und Beschaffung. 5.Auflage. Springer, Berlin 2014.

4. SCHUH, G.: Produktionsplanung und -steuerung. Grundlagen, Gestaltung und Konzepte. 3., völlig neu bearb. Aufl. Springer, Berlin 2006.

5. MOIZER; ELKADY; LIU: A Decision Support Framework to Assess Grocery Retail Supply Chain Collaboration: A System Dynamics Modelling Approach. In: International Journal of Innovation, Management and Technology 2014 (2014) 5, S. 232 - 238.

6. LANGROODI, R.; AMIRI, M.: A system dynamics modeling approach for a multi-level, multi-product, multi-region supply chain under demand uncertainty. In: Expert Systems With Applications 51 (2016) p.231-244

7. HISHAMUDDIN, H.; SARKER, R.; ESSAM, D.: A Simulation Model of a Three Echelon Supply Chain System with Multiple Suppliers subject to Supply and Transportation Disruptions. In: IFAC-PapersOnLine 48-3 (2015) 2036-2040

8. LI, C.; REN, J.; WANG, H.: A system dynamics simulation model of chemical supply chain transportation risk management systems. In: Computer and Chemical Engineering 89 (2016) 71-83

9. STICH, V.; PAUSE, D.; BLUM, M.; HINRICHS, N.: A Simulation based Approach to investigate the Procurement Process and its Effect on the Performance of Supply Chains. Springer, 2016.

10. FORRESTER, J. W.: Industrial Dynamics. The M.I.T. Press, Cambridge 1961.

11. COYLE, R.G.: System dynamics modelling. A practical approach. Chapman \& Hall, London 1996.

12. ABERLE E.: Management der Logistikkette. Kostensenkung - Leistungssteigerung - Erfolgspotential. Fachtagung der Deutschen Gesellschaft für Logistik e.V. 9. Hrsg.: H.-C. Pfohl. Schmidt, Berlin 1994.

13. WIENHOLDT, H: Dynamische Konfiguration der Ersatzteillogistik im Maschinen- und Anlagenbau. 1. Aufl. Apprimus-Verl., Aachen 2011.

14. GRUEN, O; JAMMERNEGG, W.; KUMMER, S.: Grundzuege der Beschaffung, Produktion und Logistik. 2. Aufl., Pearson Studium, München 2010. 